\title{
OS ATINGIDOS POR BARRAGENS: REFLEXÕES E DISCUSSÕES TEÓRICAS E OS ATINGI- DOS DO ASSENTAMENTO OLHOS D’ÁGUA EM UBERLÂNDIA-MG
}

\section{The affected people by dams: Reflections and theoretical discussions and those affected from Olhos D`água settlement in Uberlândia-MG}

\author{
Rene Gonçalves Serafim Silva \\ Licenciado em Geografia pelo Instituto de Geografia - UFU \\ Uberlândia/MG - Brasil \\ renegoncalves_geo@yahoo.com.br \\ Vicente de Paulo da Silva \\ Professor Doutor do Instituto de Geografia - UFU \\ Uberlândia/MG - Brasil \\ vicente@ig.ufu.br
}

Artigo recebido em 23/02/2011 e aceito para publicação em 18/10/2011.

RESUMO: Objetivou-se neste trabalho discutir o conceito de atingido, utilizado atualmente pela comunidade cientifica para denominar aqueles que sofrem de alguma forma com as construções de barragens, refletindo e debatendo as concepções teóricas do termo e suas variações. Para tanto é utilizada a conceituação mais recente, e em uso, tanto do meio acadêmico quanto institucional. Os atingidos, consequência dos grandes empreendimentos hidrelétricos, são aqueles que foram desprovidos de morar ou trabalhar em áreas alagadas ou próximas das barragens das usinas, acarretando em perdas territoriais e transformando as identidades destes indivíduos. Utilizou-se, como estudo de caso, o assentamento Olhos D'água, localizado no município de Uberlândia-MG, demonstrando como os atingidos por barragens precisam modificar seus modos de vida, e como isso resulta na transformação das relações socioculturais, estabelecidas anteriormente, após a chegada das usinas hidrelétricas que fazem parte do Complexo Energético Amador Aguiar.

Palavras-chave: Grandes Projetos de Investimento. Atingido. Assentamento Olhos D’água.

\begin{abstract}
This work aims to discuss the concepts of affected used currently by the scientific community to name those who suffer in some way with the construction of dams, reflecting and debating theoretical conceptions of the term and its variations. It is applied the most current and conceptualization in use by academic community or agencies. The affected, as a result of large hydroelectric development projects, are those who were deprived of living or working in flooded areas or close to power plant, causing territorial losses and changing the identities of these people. As a study of case, Olhos D'água settlement, located in Uberlândia-MG, Brazil, proves how affected people need to modify their livelihoods, resulted of the transformation of cultural relations entered into before and after the arrival of hydroelectric power stations which are part of the energy complex named as Amador Aguiar.
\end{abstract}

Keywords: Large Development Project. Affected. Olhos D’água settlement. 


\section{INTRODUÇÃO}

As barragens construídas no Brasil para atender a demanda por produção de energia elétrica, por meio de usinas hidrelétricas, são desde a década de 1950 o que podemos chamar de Grandes Projetos de Investimento (GPIs). Este conceito não é novo e são assim chamados por serem

\section{(...) empreendimentos que consolidam o pro-} cesso de apropriação de recursos naturais e humanos em determinados pontos do território, sob lógica estritamente econômica, respondendo a decisões e definições configuradas em espaços relacionais exógenos aos das populações/regiões das proximidades dos empreendimentos (VAINER; ARAÚJO, 1992, p. 34)

São, portanto, empreendimentos que visam à apropriação e reprodução do espaço sob a lógica economicista, desenvolvimentista e exploratória de recursos naturais, desconsiderando as populações que vivem e possuem algum vínculo material ou imaterial com o local que sofrerá a ação deste. Muitas vezes são populações que jamais saíram de seus lugares e que possuem uma relação histórica com estes territórios que ocupam, sendo eles o palco de suas manifestações culturais, sociais e de trabalho, onde nem sempre impera a lógica do capital industrial-financeiro do mundo contemporâneo.

Os grandes empreendimentos, outra terminologia para Grandes Projetos de Investimento, trata-se de "projetos econômicos de envergadura, como hidrelétricas, rodovias, planos de colonização, de grande impacto social e ambiental, mas que não têm por destinatárias as populações locais" (MARTINS, 1993, p. 61-62). Portanto, na concepção desse autor, são empreendimentos que favorecem a economia em detrimento das populações atingidas.

Dentro deste contexto, surge uma categoria de análise nas ciências humanas que se ocupa em estudar os efeitos socioespaciais que as barragens impõem: o atingido. Antes de qualquer coisa, o atingido é aquele que de alguma forma sente os efeitos da construção e operação de uma usina hidrelétrica, podendo ou não ser deslocado compulsoriamente para áreas diferentes àquela que ocupava. Ou, então, deslocados para áreas distantes geograficamente do espaço em que habitavam. O deslocamento não se trata exclusivamente da situação de proprietários de terras que serão alagadas pela formação do lago. Existe também o deslocamento das pessoas que não tiveram terras alagadas pelas águas do reservatório, que não eram proprietários, mas que trabalhavam nas áreas inundadas ou próximas, e, por este motivo, tiveram suas relações de trabalho transformadas pela construção do empreendimento.

Pode-se enumerar uma série de relações de trabalho que são cessadas com a construção de grandes empreendimentos: comerciantes fornecedores de produtos a moradores das áreas antes da inundação, trabalhadores-artesãos que se utilizavam dos recursos naturais como matéria-prima para produção de seus produtos, trabalhadores assalariados, enfim, cada área inundada possui especificidades e particularidades quanto aos deslocados economicamente. Há ainda, tão importante quanto, os atingidos que historicamente estão assentados sobre o território a ser inundado: os indígenas, os ribeirinhos, os quilombolas, até mesmo um distrito municipal inteiro, mobilizando contingentes populacionais consideráveis.

Pensar sobre estes atingidos é fazer um exercício de reflexão e discussão, visto que o Brasil está investindo pesadamente na construção de novas usinas hidrelétricas. Estas têm se instalado prioritariamente em áreas polêmicas como a região amazônica, cujos estudos de seus impactos e efeitos, sobre o ambiente natural e social, incitaram o questionamento da comunidade acadêmica sobre a veracidade e aprofundamento da questão, além de promover a organização de movimentos socioambientais e indígenas contra as obras nas bacias dos rios da Amazônia.

O Cerrado também merece destaque no cenário atual de implantação de hidrelétricas no Brasil por ser local de grupos sociais tradicionais, e também um domínio morfoclimático de elevado potencial hidráulico, propício à implantação de empreendimentos hidrelétricos devido ao potencial hídrico e relevo favorável à formação de lagos e barragens. Além disso, há que se pensar no panorama atual da relação território-capital, ultrapassando os conceitos de estado-nação tradicionais na geografia. Neste sentido, Ferreira e Mendonça (2008, p. 2, grifo do autor) 
trazem à tona outra questão que é a territorialização do "hidronegócio", conforme citação a seguir:

\section{A territorialização do hidronegócio (transfor- mação da água em negócio), especialmente em áreas de Cerrado, caracteriza-se como uma das formas de reestruturação produtiva do capital, que vem ocasionando significativas alterações nas relações de trabalho e na ação política dos trabalhadores.}

Deste modo, a implantação de um grande empreendimento hidrelétrico não está relacionada apenas à questão energética e de criação de infraestrutura, mas de transformação deste processo em negócio, visto a demanda crescente e lucrativa de projetos deste âmbito. Destaca-se que os autores apresentam no decorrer do trabalho uma perspectiva semelhante à abordada aqui em relação ao estudo de caso selecionado.

Embora o conceito de atingido seja encontrado em artigos, livros e publicações anteriores, o termo sempre gera muita confusão, controvérsia e, talvez, desconhecimento por se tratar das populações que sofrem com a chegada de uma usina hidrelétrica, confundindo-se com a noção de alagado ou inundado. Ainda que, em certos momentos, atingido seja também o inundado, estes são termos análogos. Ampliar a discussão acerca da terminologia possibilita refletir sobre a (re) construção do conceito, bem como fomentar a utilização deste frente as novas diretrizes econômicas e desenvolvimentistas que o governo Luiz Inácio Lula da Silva engendrou ao longo de seus 8 anos de governo, e que provavelmente continuarão nos próximos anos do governo Dilma Rousseff. Pauta-se em um desenvolvimento do modelo energético brasileiro regulado em duas grandes fontes de energia: o petróleo proveniente das camadas do pré-sal e a energia hidroelétrica com a construção de novas barragens. $\mathrm{O}$ foco do artigo em questão se situa apenas na segunda fonte energética.

Objetivou-se, deste modo, realizar uma reflexão e discussão teórica sobre o conceito de atingido, buscando compreender quem são esses "sujeitos" e para onde vão quando são deslocados de seus territórios, utilizando-se para tanto um estudo de caso. Para compreender as particularidades que cada grupo de atingido possui, utilizou-se de entrevistas de uma pesquisa em andamento, dos próprios autores deste artigo, como forma de ilustrar a situação dos atingidos em um pequeno assentamento rural localizado no município de Uberlândia-MG.

Este artigo integra um projeto mais amplo, intitulado "Grandes Projetos de Investimentos no Triângulo Mineiro e Alto Paranaíba: o rio Araguari passo a passo e os efeitos sócio-espaciais da construção de barragens", financiado pela Fundação de Amparo à Pesquisa do Estado de Minas Gerais (FAPEMIG) em parceria com a Universidade Federal de Uberlândia (UFU), de acordo com o Edital Universal 01/2009.

\section{METODOLOGIA}

Para a realização deste artigo, empregou-se como referência de abordagens e concepções teóricas, sobre o termo atingido e seus derivados, os estudos de Vainer (2008), as definições da Comissão Mundial de Barragens (World Commission on Dams) divulgadas em 2000 e, por último, o Decreto no 7.342 de 26 de outubro de 2010, recentemente publicado pela Presidência da República no Diário Oficial da União, que instituiu o cadastro socioeconômico para identificação, qualificação e registro público da população atingida por empreendimentos de geração de energia hidrelétrica. Para demonstrar "quem são" e "para onde vão" as populações atingidas, trabalhou-se com os atingidos do assentamento rural Olhos D'água, no município de Uberlândia-MG, por serem moradores que perderam seus "territórios" culturais e de trabalho a partir da construção do Complexo Energético Amador Aguiar, situado na Bacia Hidrográfica do Rio Araguari.

O recorte espacial utilizado neste artigo objetivou caracterizar uma forma de atingido que está situado em área de Cerrado, contrastando com os atingidos de Itaipu ou dos rios da bacia amazônica, que são mais conhecidos pela população não-acadêmica e pela imprensa no geral. Quanto ao recorte temporal, empregou-se um recorte mais recente. Embora as usinas do complexo energético que deslocaram os moradores para o assentamento já estejam em pleno funcionamento, é possível visualizar uma forma recorrente e histórica de tratar os atingidos por barragens. 
As informações referentes aos atingidos que atualmente vivem no assentamento Olhos D'água foram coletadas por meio de entrevistas gravadas, registros fotográficos e observações empíricas in loco. No entanto, por ainda ser uma pesquisa em andamento, as informações contidas nas gravações estarão relatadas de forma indireta pelos autores, preservando a identidade dos assentados. Ressalta-se que todas as gravações realizadas com os pesquisados, e as fotografias obtidas nos trabalhos de campo, foram previamente autorizadas pelos assentados por meio de documento escrito, assinado (pelo pesquisador e entrevistado) e lido em gravação de áudio antes que as informações fossem coletadas.

\section{DISCUSSÃO TEÓRICA}

Várias são as concepções de atingidos, elaboradas a partir daquilo que se considera como base técnica e econômica na definição de "atingido". Mas antes de tudo, Vainer (2008, p.40) alerta que "a noção não é nem meramente técnica, nem estritamente econômica", ou seja, é necessário que haja um equilíbrio entre as questões técnicas e econômicas na delimitação da terminologia.

Dentre as concepções discutidas por Vainer (2008), pode-se destacar, primeiramente, a concepção territorial-patrimonialista, na qual o atingido são os proprietários de terra. As medidas de negociações e reassentamento destes proprietários apresentam um caráter indenizatório das terras desapropriadas para construção da barragem e enchimento do reservatório. Embora o atingido aqui seja o proprietário, o autor faz uma ressalva e inclui aqueles que trabalham em um pedaço de terra sob posse, e que possui benfeitorias. Acabam assim, entrando nesta concepção de atingido, por serem indenizados pelo valor das benfeitorias realizadas.

A outra visão debatida pelo autor é a concepção hídrica, no qual o atingido passa a ser o inundado, ou seja, aquele que do ponto de vista prático teve suas terras alagadas. Reconhece também os não proprietários de terras, mas que nela trabalham, apesar de delimitar apenas aqueles que perdem suas atividades/ terras no limite do reservatório. Relega-se, assim, aqueles que sofrem com os efeitos do empreendimento devido a proximidade com o projeto a ser executado.

De acordo com Vainer (2008, p. 44),

A única forma de superar de maneira consistente as concepções que têm como núcleo o direito do empreendedor, e não os direitos das populações afetadas, é entender a natureza do processo social deflagrado pelo empreendimento, processo simultaneamente econômico, político, cultural e ambiental. Trata-se, com efeito, de um processo de mudança social que interfere em várias dimensões e escalas, espaciais e temporais.

Compreende-se que as concepções abordadas pelo autor vão, na verdade, atender aos interesses dos atores hegemônicos da relação de conflito que se estabelece nos Grandes Projetos de Investimento, e que é preciso superá-las. Desta forma, é imperativo criar no âmbito acadêmico discussões densas e profundas acerca da problemática teórica exposta, uma vez que as populações afetadas pelos grandes empreendimentos são, de fato, os maiores prejudicados destas mudanças sociais ocasionadas por agentes exteriores a eles.

Por modificar as estruturas socioeconômicas pré-estabelecidas, é preciso aprofundar as discussões e propor resoluções entre os sujeitos envolvidos no conflito que se instala, sendo que o Estado, representado pelas agências estatais, não pode se furtar do papel de mediador e representante do grupo social atingido. Na prática, os atingidos ainda têm de se organizar por meio de movimentos sociais para reivindicarem suas perdas, ficando as concessionárias de energia e as agências do setor elétrico alheias ao processo de desterritorialização que se processa na implantação de uma usina hidrelétrica.

Um exemplo de luta pelo reconhecimento e legitimação de sua condição pode ser encontrado no relato de Germani (2003) em relação aos atingidos de Itaipu, cuja riqueza de detalhes e propriedade acadêmica, sem fugir da narrativa sequencial que descreve o recorte temporal adotado pela autora, torna-se uma obra de fundamental importância para aqueles que se propõe a mergulhar nos estudos sobre a temática. No caso de Itaipu, com base na interpretação do relato 
da autora, é possível observar o papel que o poder público, concessionárias e agências do setor elétrico exercem sobre a população a partir do discurso oficial impregnado de ufanismo e, por trás disso, a busca pelo cerceamento do direito dos atingidos, inclusive de discutir a possibilidade, ou não, de implantação do empreendimento.

No documento apresentado pela Comissão Mundial de Barragens, intitulado "Deslocamento, Reassentamento, Reabilitação, Reparação e Desenvolvimento" (WCD, sigla em inglês, 2000, tradução nossa), elaborado por Bartolome e outros (2000), pretende-se debater com os conceitos apresentados no título do documento e desenvolvidos com experiências mundiais em relação à construção de barragens, não um aprofundamento no documento. Com relação ao termo "deslocamento", Bartolome e outros (2000) dirão que se trata de um movimento involuntário na maioria das vezes, com pouca participação significativa da população atingida. Os afetados (tradução literal da palavra affected, o que equivaleria a atingidos no português), de acordo com a Comissão Mundial de Barragens,

têm sido, assim como os deslocados, freqüentemente os últimos a receber qualquer informação significativa do projeto de barragem. Que as informações que eles recebem são tipicamente limitadas e fornecidas muito tarde no planejamento e implementação de medidas mitigadoras (BARTOLOME et al., 2000, p.3, tradução nossa).

O documento em questão ainda informa que o deslocamento "refere-se não somente àqueles que são forçados a se relocarem fisicamente a fim de realização do projeto e seus aspectos relacionados, mas também incluem aqueles que são deslocados de seus recursos básicos e meio de vida" (BARTOLOME et al., 2000, p.3, tradução nossa). Retorna-se, portanto, à concepção de deslocamento econômico, no qual o meio de vida, o sustento de um grupo social é interrompido pelo empreendimento.

A questão da comunicação, bastante difundida na atualidade como forma de esclarecimento e discussão da problemática da implantação, e operação, das usinas hidrelétricas, se esbarra nas condutas perversas geradas por concessionárias ou agências do setor elétrico para desarticular qualquer movimentação dos grupos atingidos, conseguindo concretizar a implantação dos projetos elétricos por meio do discurso do desenvolvimento local e regional.

Todavia, as áreas receptoras de uma usina hidrelétrica apresentam um crescimento econômico temporário apenas no momento de pico da obra, sendo confundido com desenvolvimento regional (BORTOLETO, 2001). Concessionárias e Estado justificam que os sacrifícios de alguns vão, em longo prazo, beneficiar a grande maioria (BARTOLOME et. al., 2000).

A compensação, de acordo com o documento da WCD,

refere-se a medidas especificas que pretendem reverter a perda sofrida pelos atingidos ou aqueles afetados de forma negativa devido a barragem. A compensação geralmente assume a forma de uma indenização única, em dinheiro [...] na maioria das vezes são recompensados somente os proprietários. Arrendatários, meeiros, trabalhadores assalariados, artesãos e posseiros são raramente considerados elegiveis para compensação, ao passo que eles são, paradoxalmente, os mais vulneráveis e necessitados de apoio (BARTOLOME et al., 2000, p.4, tradução nossa).

Esta concepção aproxima-se muito daquela denominada de territorial-patrimonialista discutida por Vainer (2008), onde os proprietários são os maiores beneficiados, sem, contudo, serem os verdadeiros atingidos do ponto de vista social. Esta visão de compensação deve ser superada no âmbito das negociações realizadas entre atingidos e empreendedores quando uma obra se instala em alguma porção do território.

Tendo em vista que os atingidos demandam outras áreas quando da operação do empreendimento, precisa-se teorizar acerca do reassentamento e reabilitação destas populações. Neste contexto, Bartolome e outros (2000) apresentam no documento ora discutido os seguintes problemas destas etapas: 
- A relocação física após as primeiras notificações é demorada. Nesse período entre a notificação e a efetiva mudança os atingidos sofrem com as incertezas, acarretando em ansiedade psicossocial;

- Os custos para o reassentamento são subestimados e reduzidos;

- A participação dos atingidos é superficial ou tratada como desimportante pelos responsáveis pelo projeto. Freqüentemente são manipulados, cooptados ou excluídos;

- Experiências que envolvem grupos nativos e indígenas são extremamente negativas em termos de cultura, economia e saúde;

- Relocação forçada resulta em pessoas sendo transplantadas de uma ecologia social na qual elas foram atores primários, para uma em que são "estranhas";

- Terrenos de reassentamento têm sido pouco preparados em termo de amenidades básicas e essenciais de infraestrutura como saúde, educação e crédito.

Poder-se-ia listar mais problemas referentes à questão do reassentamento e reabilitação daqueles que tiveram de deixar seu território compulsoriamente. Entretanto, estes acima apresentados são os mais importantes do documento analisado.

A reabilitação "é realmente um efeito do reassentamento que é concebido não como uma relocação física ou mera restauração dos ganhos, mas como desenvolvimento" (BARTOLOME et al., 2000, p.8, tradução nossa). Entende-se, nesse contexto, que reabilitação e reassentamento são concepções distintas, mas que se planejadas no sentido de desenvolvimento das populações atingidas nas áreas relocadas, em um determinado momento podem convergir para a mesma direção, tornando-os conceitos complementares.

Recentemente no Brasil houve, a princípio, um avanço na legislação no que tange aos atingidos. Ainda é prematuro fazer qualquer consideração no sentido de melhoria, pois o mecanismo criado para cadastrar as populações atingidas ainda não foi colocado em prática. Instituiu-se por meio do Decreto $\mathrm{n}^{0} 7.342$ de 26 de outubro de 2010, o cadastro socioeconômico, como instrumento de identificação, qualificação e registro público da população atingida por empreendimentos de geração de energia hidrelétrica. Destaca-se de imediato uma premissa, que até o momento não aconteceu, do parágrafo único do artigo $1^{\circ}$, no qual "deverá ser assegurada ampla publicidade ao cadastro de que trata este Decreto" (BRASIL, 2010). Houve apenas algumas notas na imprensa nacional referente à publicação do decreto, mas a divulgação em massa $\mathrm{e}$ programas institucionais que promovam efetivamente a utilização do cadastro ainda não foi detectada.

No III Encontro Latinoamericano de Ciências Sociais e Barragens, realizado na cidade de Belém-PA em dezembro de 2010, foi abordado o referido decreto na Mesa Redonda "As barragens de Belo Monte: processo decisório, licenciamento e conflitos" na apresentação de Felício Ponte Jr., procurador federal do Ministério Público. De acordo com o debate ocorrido na mesa redonda, o procurador destacou o avanço deste decreto na legislação, embora ainda muito incipiente e que se aplicará apenas aos empreendimentos a serem licenciados a partir de janeiro de 2011.

A crítica que se faz é quanto aos demais empreendimentos já existentes ou licenciados, e que não utilizariam a ferramenta do cadastro ou estariam isentos da obrigação de cadastrar os atingidos. Outro ponto negativo do decreto e que poderia ser revisto está na falta de diálogo com o Movimento dos Atingidos por Barragens (MAB), uma vez que no decreto existirá um comitê interministerial que atuará nas funções de realizar ou esclarecer as concessionárias quanto à elaboração do cadastro dos atingidos. Como o movimento é a classe que representa os atingidos por barragens, semelhante às funções dos sindicatos trabalhistas, o MAB deveria trabalhar em conjunto com os ministérios por ser a parte mais importante envolvida no cadastro. 


\section{OS ATINGIDOS DO ASSENTAMENTO OLHOS D’ÁGUA}

O assentamento Olhos D'água, localizado no município de Uberlândia-MG, foi criado a partir do momento em que começaram as desapropriações na Bacia do Rio Araguari no trecho que compreende o Complexo Energético Amador Aguiar. É composto, originalmente, por atingidos que se enquadraram na concepção de deslocados econômicos, pois perderam seus trabalhos nas propriedades que foram alagadas pelo enchimento do reservatório. Embora o complexo energético tenha iniciado suas atividades de obras em setembro de 2003 e o assentamento das famílias atingidas que optaram pela relocação rural também neste período, as escrituras dos imóveis só foram entregues em 14 de outubro de 2010. Esta lentidão no processo de escrituração dos imóveis acarreta diversos entraves no desenvolvimento das famílias assentadas, dado que muitos financiamentos e créditos rurais necessariamente envolvem a garantia da posse da terra.

As negociações, com relação às áreas a serem relocadas, não foram discutidas durante o processo de apresentação e viabilização das duas usinas que compõem o complexo energético. De acordo com os assentados, o local onde situa o assentamento já existia quando souberam que deveriam se deslocar para outra área, em função da construção do empreendimento. Desta forma, não houve dentro das negociações um momento no qual os assentados, juntamente com a concessionária, discutiriam os rumos e formas de reassentamento das famílias. As glebas de terras já tinham sido loteadas a partir de uma grande propriedade, adquirida pelo consórcio responsável pela construção da usina. Coube aos assentados apenas a participação no sorteio que ocorreu para que as "chácaras" (denominação dos assentados referente às suas terras) fossem escolhidas. De certa forma foi a maneira mais democrática de escolha das terras.

Ainda que os assentados da comunidade Olhos D'água não fossem proprietários de terra, eles mantinham uma relação de trabalho, e simbólica/cultural, com as áreas que hoje estão alagadas na Bacia do Rio Araguari. Os relatos até o momento registrados mostram que os chefes de família trabalhavam no sistema patronal, no qual recebiam mensalmente seus ganhos pelo trabalho realizado e, ainda, mantinham com a terra uma cultura de cultivo das áreas não utilizadas pelo proprietário. Todos os produtos gerados pelo cultivo familiar eram revertidos na composição da dieta alimentar das famílias, não sendo comum a venda destes produtos a terceiros. O que se observa atualmente é que os moradores das chácaras ainda carregam esta cultura, que não está voltada para o comércio de seus produtos.

Durante o processo de relocação da população atingida, houve cursos promovidos pelo Consórcio Capim Branco Energia (CCBE) referente ao aproveitamento das frutas excedentes na confecção de doces para ser comercializados e gerar renda aos assentados. No entanto, a cultura local ainda não conseguiu absorver essa forma de relação capitalista no interior de suas chácaras. A Figura 1 mostra que parte dos alimentos não consumidos ou doados a terceiros são perdidos devido alguns assentados não terem incutido em sua cultura o empreendedorismo, ou seja, estão vinculados ainda às suas práticas culturais de antes, no qual os alimentos são consumidos ou doados. 
Figura 1: Frutas "perdidas" de uma das chácaras.

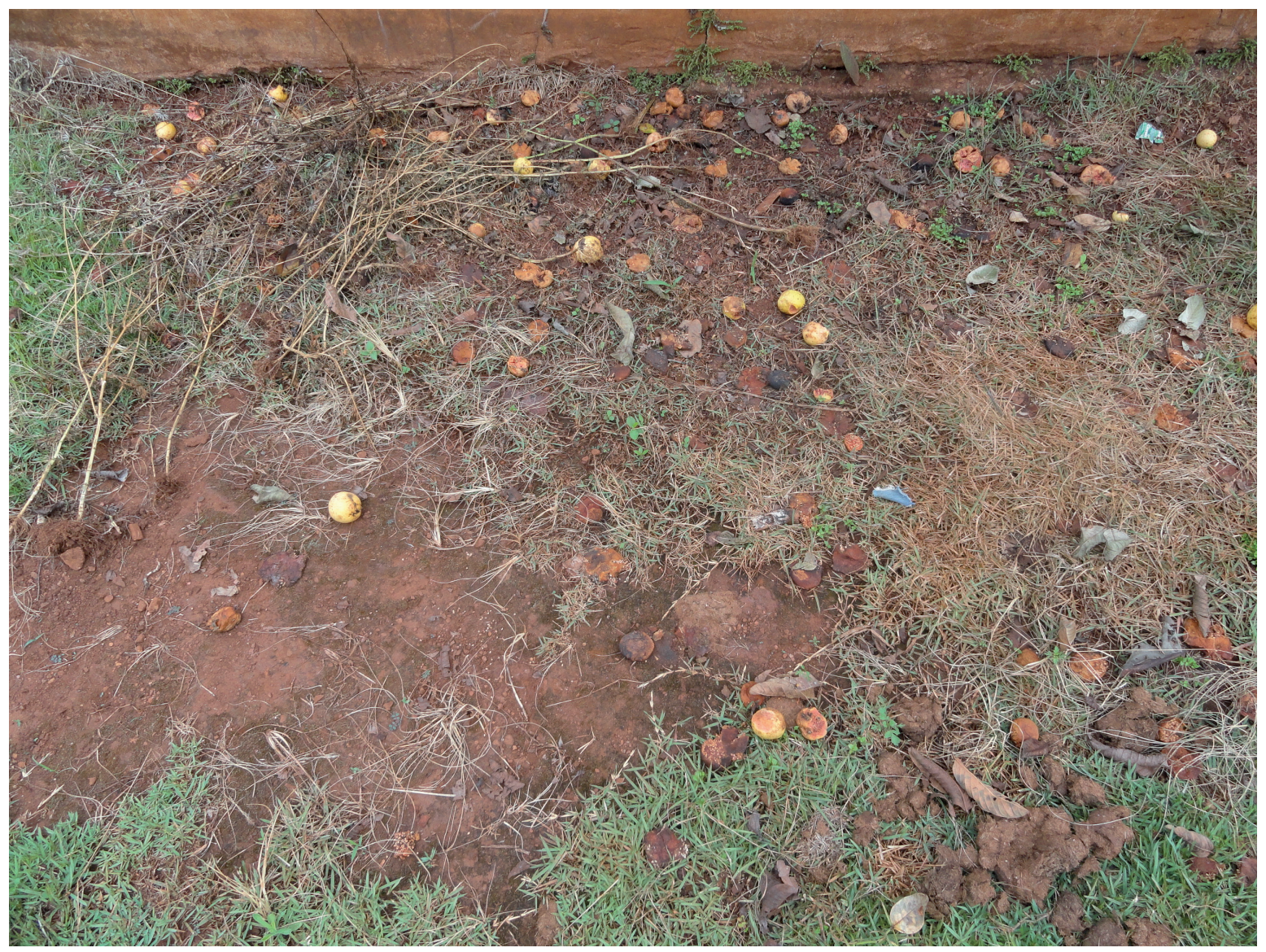

Foto: SILVA, R. G. S., 2011.

De acordo com as informações coletadas, e o que se observou nos trabalhos de campo, os moradores do assentamento estavam acostumados com a relação assalariada e, portanto, a produção não era voltada ao comércio, mas para o consumo. E aquilo que não era utilizado era descartado naturalmente na própria natureza. $\mathrm{O}$ caso mostrado acima não é único. Além das goiabas mostradas na Figura 1, a produção de banana e outras frutas também têm como destino, quando não consumidos ou manufaturados, o chão dos quintais que neles assentam seus cultivos.

Com relação ao aspecto cultural e simbólico, as águas do rio foi o assunto mais abordado nas conversas com os assentados. Segundo os relatos, o rio, que foi substituído por um rego d'água no assentamento, é a maior perda simbólica e que não pode ser reproduzida nas chácaras. $\mathrm{O}$ aspecto simbólico e cultural que o rio representa está tanto na pesca, esportiva ou para o consumo, quanto no lazer das famílias que lá trabalhavam. De acordo com seus relatos, o rio era também ponto de encontro das famílias e amigos nos momentos de descanso, representando um elo social e de manifestação das relações de amizade.

Este território cultural se perdeu com o deslocamento das famílias e representá-lo na forma de um rego causa aos assentados um sentimento de frustração e comoção ao mesmo tempo. A criatividade e o próprio conhecimento acumulado nos anos de trabalho com a terra fez com que alguns assentados pudessem criar, ainda que de forma precária e em pequenas quantidades, peixes no rego que corta as chácaras. A técnica é bem rudimentar, mas que gera aos assentados uma forma de utilização da carne do peixe na alimentação cotidiana. Consiste em cercar lados opostos do rego d'água, de cerca de 2 a 3 metros de distância, e fazer a ceva para que os peixes que passem pela grade, com o passar do tempo, fiquem maiores, impedindo, devido à largura da passagem da grade, que eles continuem o

Soc. \& Nat., Uberlândia, ano 23 n. 3, 397-408, set/dez. 2011 
curso d'água. Assim, uma pequena criação de peixe é utilizada não mais como lazer pelos assentados, mas como meio de sustento e variação da dieta alimentar.

A Figura 2 é uma amostra do rego d'água presente no assentamento Olhos D'água. A finalidade resulta em utilização das águas para promover apenas a irrigação de algumas culturas, além da piscicultura rudimentar em algumas chácaras. As outras formas de utilização das águas foram cessadas devido às proporções do tamanho do canal. Deste modo, pode-se dizer que os assentados foram desprovidos de suas atividades afetivo-simbólicas, resultando em um "processo de exclusão social, ou melhor, de exclusão socioespacial" (HAESBAERT, 2006, p.67). Embora a obtenção de uma propriedade, com escritura e todos os direitos legais, seja uma aspiração dos assentados ou de qualquer outro trabalhador rural, ocorreu nas relações, que se processam no âmbito cultural, um movimento que se pode denominar de "desterritorialização culturalista”. Este termo, dentro da perspectiva geográfica, é

percebida a partir de uma leitura do território como fonte de identificação cultural, referência simbólica que perde sentido e se transforma em um "não-lugar". Estes "não-territórios", culturalmente falando, perdem o sentido/o valor de espaços aglutinadores de identidades, na medida em que as pessoas não mais se identificam simbólica e afetivamente com os lugares em que vivem, ou se identificam com vários deles ao mesmo tempo e podem mudar de referência espacial-identitária com relativa facilidade. (HAESBAERT, 2009, p.131).

Figura 2: Rego d'água que passa pelas chácaras

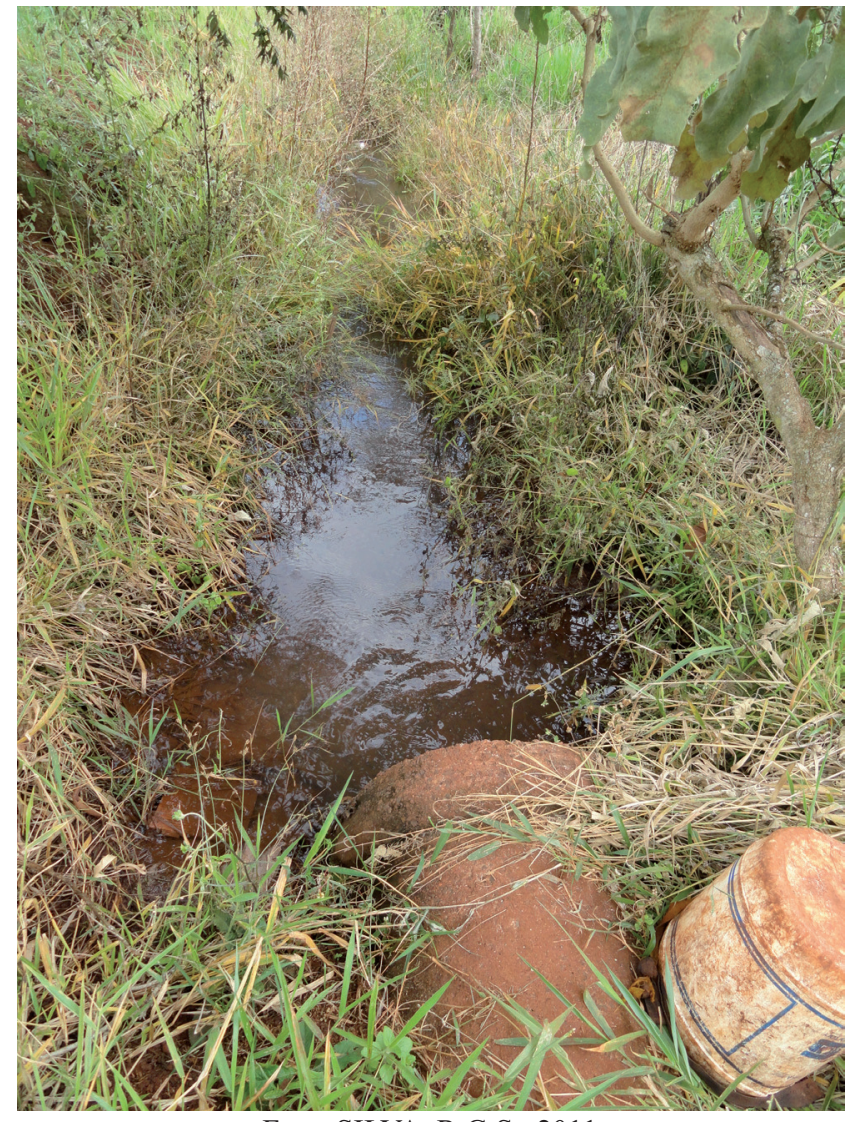

Foto: SILVA, R.G.S., 2011 
Em um primeiro momento, com a falta do rio e das atividades relacionadas a ele, o assentado encarou seus respectivos lotes como um "não-lugar", uma vez que sofreram, ainda que sem perceberem, um processo de reterritorialização no interior de suas chácaras. Com o passar do tempo, os assentados foram se identificando com aspectos diversos de seus lotes, preenchendo uma lacuna deixada pela falta do rio nas proximidades de suas casas. Como forma de ilustrar e perceber como esse processo de "referência espacial-identitária" muda com o tempo e com facilidade, em uma das entrevistas o assentado em questão fez referência à uma antiga casa, presente em seu lote, como objeto de identificação no momento de escolha do mesmo. De acordo com o relato do morador, a presença da antiga sede da fazenda em seu território fez com que ele escolhesse, no momento do sorteio dos lotes, aquele em que hoje mora. Isso remete às questões expostas por Haesbaert (2009) em sua definição de desterritorialização culturalista, mas ao mesmo tempo um processo de reterritorialização dos aspectos relativos ao simbólico e afetivo.

\section{CONSIDERAÇÕES FINAIS}

Repensar e teorizar sobre quem são os atingidos por barragens é considerar uma parcela importante da população brasileira, visto o cenário atual de crescimento econômico e, consequentemente, aumento do número de usinas hidrelétricas instaladas em território nacional para geração de energia elétrica. Discutir o conceito também esclarece para a comunidade acadêmica as diferenças e existência de várias formas de ser um atingido, sem valorizar um tipo em detrimento de outros.

Existe um número considerável de estudos sobre os impactos de usinas hidrelétricas em várias áreas do conhecimento, no entanto estes se limitam na maioria das vezes aos impactos ambientais. Faz-se necessário, portanto, estudos que avaliem os efeitos, e não somente os impactos, que os Grandes Projetos de Investimento (GPI) causam ao território e às populações que o habitam, principalmente os territórios simbólicos e imateriais, que neste caso também são territórios de trabalho e poder.

No contexto do Triângulo Mineiro, no esta- do de Minas Gerais, existe um número crescente de pesquisas relacionadas aos efeitos socioespaciais que os grandes empreendimentos imprimem sobre a população desta região. No Instituto de Geografia (IG), da Universidade Federal de Uberlândia (UFU), um grupo de professores-pesquisadores e alunos de graduação e pós-graduação formou o Núcleo de Estudos e Pesquisas sobre Efeitos de Grandes Empreendimentos (NEPEGE) que visa estudar estes efeitos, estendendo seus resultados para a comunidade científica e para aqueles que se interessam pelo assunto.

Em relação aos atingidos pelas barragens construídas pelo Consórcio Capim Branco Energia e que hoje são moradores do assentamento Olhos D'água, pode-se denominá-los de deslocados econômicos devido ao fato de suas relações de trabalho terem sido cessadas com a chegada das usinas hidrelétricas. Assim, as pessoas para quem trabalhavam foram indenizadas pelo princípio territorial-patrimonialista discutido, no qual as propriedades foram alagadas, enquanto que eles foram indenizados pela relação de trabalho interrompida permanentemente.

Embora o objetivo da pesquisa e o direcionamento das entrevistas não tenha sido a questão estritamente econômica, não se pode deixar de destacar as mudanças e transformações nas relações de trabalho dos assentados. Se antes eram trabalhadores assalariados, hoje são os proprietários de suas terras, o que não significa que é a melhor opção na visão deles, pois quase a totalidade dos atingidos/assentados não conseguem sobreviver daquilo que é produzido e realizado nas chácaras. Precisam complementar suas rendas com trabalho fora do assentamento quase que diariamente.

A questão cultural foi observada como algo que transformou a vida cotidiana dos moradores do assentamento Olhos D'água. Os objetos e referenciais que identificavam e que faziam parte do dia-a-dia foram transformados ou extintos, como é o caso do rio. O principal elemento simbólico-cultural, o "rio das velhas", como era constantemente chamado e conhecido pelos moradores o rio Araguari, foi palco de manifestações sociais entre a população que outrora vivia o rio como ponto de encontro das famílias e amigos para lazer, além do trabalho.

Por fim, estudar estes atingidos como estu- 
do de caso é possibilitar que as transformações que ocorreram, e ainda ocorrem, no interior desta parcela da sociedade seja registrada e compreendida, favorecendo em negociações futuras, uma maneira menos traumática de realizar os deslocamentos que se façam necessários.

\section{REFERÊNCIAS}

BARTOLOME, L. J. et al. Displacement, Resettlement, Rehabilitation, Reparation, and Development. WCD Thematic Review I.3 prepared as an input to the World Commission on Dams. Cape Town, 2000. Disponível em: http://www.dams.org/. Acesso em: 12 out. 2010.

BORTOLETO, E. M. A implantação de grandes hidrelétricas: desenvolvimento, discurso e impactos. Geografares, Vitória, no 2, 2001. Disponível em: http://www2.cchn.ufes.br/geoufes/ geografares/?N\%FAmeros_publicados:Nr._02. Acesso em: 04 ago. 2010.

BRASIL. Decreto n. 7.342, de 26 de outubro de 2010. Presidência da República, Brasília, DF. Disponível em: http://www.planalto.gov.br/ccivil 03/ Ato20072010/2010/Decreto/D7342.htm. Acesso em: 12 de out. 2010 .

ENCONTRO LATINOAMERICANO DE CIÊNCIAS SOCIAIS E BARRAGENS, 3., 2010, BELÉM. Anais... Belém: Biblioteca do NAEA/UFPa, 2010.

FERREIRA, A. P. da S. de O; MENDONÇA, M. R. As (re) existências nas áreas de cerrado: o caso dos trabalhadores/camponeses/ribeirinhos no vale do Rio São Marcos - Catalão/GO. In: JORNADA DO TRABALHO - DINÂMICA TERRITORIAL DO TRABALHO NO SÉCULO XXI: EM BUSCA DOS SUJEITOS QUE PODEM EMANCIPAR A SOCIEDADE PARA ALÉM DO CAPITAL, 9., 2008, Catalão. Anais... Catalão: UFG/Catalão, 2008. p.1-12.
GERMANI, G. I. Expropriados Terra e Água: o conflito de Itaipu. Salvador: EDUFBA; ULBRA, 2003.

HAESBAERT, R. Territórios Alternativos. 2 ed. São Paulo: Contexto, 2009. 186 p.

HAESBAERT, R. Concepções de território para entender a desterritorialização. In: SANTOS, M. et al. Território, territórios: ensaios sobre o ordenamento territorial. 2.ed. Rio de Janeiro: DP\&A, 2006. p. 43-70.

MARTINS, J. S. A chegada do Estranho. São Paulo: Hucitec, 1993.

RAFFESTIN, C. Por uma geografia do poder. Tradução de Maria Cecília França. São Paulo: Ática, 1993.

VAINER, C. B. Conceito de "Atingido": Uma Revisão do Debate. In: ROTHMAN, F. D. (Ed.). Vidas Alagadas: Conflitos Socioambientais, Licenciamento e Barragens. Viçosa: Ed. UFV, 2008. p. 39-62.

VAINER, C. B.; ARAUJO, F. G. B. de. Grandes projetos hidrelétricos e desenvolvimento regional. Rio de Janeiro: CEDI, 1992. 88 p. 
